\title{
Improving Parent-Child Communication around Reproductive Health for Latino Teen Pregnancy Prevention
}

\author{
Caroline Leeds ${ }^{1 *}$, Kaia Gallagher ${ }^{2}$, Tara Wass ${ }^{2}$, Amber Leytem¹, Judith C. Shlay ${ }^{1}$ \\ ${ }^{1}$ Denver Public Health, Denver Health \& Hospital Authority, Denver, CO, USA \\ ${ }^{2}$ Center for Research Strategies, Denver, CO, USA \\ Email: ${ }^{*}$ Caroline.Leeds@dhha.org
}

Received 10 July 2014; revised 11 August 2014; accepted 18 August 2014

Copyright (C) 2014 by authors and Scientific Research Publishing Inc.

This work is licensed under the Creative Commons Attribution International License (CC BY). http://creativecommons.org/licenses/by/4.0/

(c) (7) Open Access

\begin{abstract}
As parent-child communication has been shown to be an effective strategy for impacting adolescent sexual activity, we evaluated the effect of implementing a parent-child connectedness curriculum with parents and youth in a predominantly Latino population with high rates of teen pregnancy. We modified two evidence-based and promising parent education curricula into five two-hour workshop sessions covering reproductive health, parenting style, adolescent development, positive reinforcement, and active listening to promote emotional support. We surveyed parents $(N=65)$ prior to and after the program and three and six months post-programming to determine how self-reported behaviors changed. Among the 65 parents enrolled, most were female, 76.9\%; Hispanic, 95.4\%; married, 70.8\%; and had less than a high school education, $60.3 \%$. Post-programming, parents reported significant and sustained improvements in ability to communicate with their youth regarding reproductive health, $p<.001$; knowledge increases about these topics, $p<.01$; more frequent initiation of reproductive health conversations, $p<.05$; more reproductive health topics discussed, $p<.001$; and improvements in connectedness with their youth, $p<.05$. The findings suggest that using a five-week parent training program improved parent-child communication. Parent-child communication programming can generate significant and sustained improvement in skills, knowledge, and confidence needed by parents to talk to their children about reproductive health. Further research is needed to assess how to replicate these results on a larger scale, particularly within high-risk populations.
\end{abstract}

\section{Keywords}

Sex Education, Program Evaluation, Parent-Child Communication

\footnotetext{
${ }^{*}$ Corresponding author.
} 


\section{Introduction}

Open communication between parents and children is strongly correlated with a reduction in teen pregnancy rates, as well as in reduced tobacco, alcohol, and other drug use; reduced high-risk sexual behaviors; and other reduced delinquent behaviors (DiClemente et al., 2001; Resnick, 1997). Thirty-eight percent of youth say that their parents influence their decisions about sex more than any other factor, but both parents and youth report that parents do not know how to talk to their children about this subject (Albert, 2012). Although rates have recently decreased, teen pregnancy and teen birth remain serious issues in the United States (Hamilton, 2012). Births to teen mothers cost United States taxpayers a total of \$10.9 billion dollars in 2008 and children of teen parents are at higher risk of negative outcomes including becoming teen parents themselves ("Teen Childbearing Cost Taxpayers \$10.9 Billion in 2008: New National and State-by-State Data Released”, 2011; Wildsmith, 2012). With adverse consequences for teen parents, their children, and economic systems, these findings underscore the need to develop and implement effective parent-child communication education around reproductive health to interrupt the cycle of teen pregnancy.

Educational interventions that improve communication around reproductive health in high-risk populations offer a potential way to improve teen pregnancy prevention outcomes. Interventions designed to strengthen parent-child communication around alcohol and other drug use have been shown to be effective (Kumpfer, 2010) as have numerous sexual behavior change interventions targeting youth (Catalano, Gavin, \& Markham, 2010; Markham et al., 2012). Although the determinants of parent-child communication about sex have been quantitatively studied, there are currently few evidence-based curricula on parent-child communication around reproductive health (Miller et al., 2011). Most programs do not target parents as key influencers of youth reproductive health behavior and additional information is needed to understand how best to improve parent-child communication around reproductive health, particularly related to increasing parent receptiveness, reaching special populations, and evaluating the sustainability of results (Kirby \& Miller, 2002; Levine, 2011).

Understanding and implementing effective parent-child communication programming around reproductive health offers particularly promising applications for high-risk populations such as Latinas where teen fertility can be 2.4 times higher than the fertility rate of non-Latina teens (Kost, 2012). However, few interventions focused on parent-child communication have been tailored to Spanish-speaking Latino communities with low literacy levels (Cardoza, Documét, Fryer, Gold, \& Butler III, 2012; Murphy-Erby, Stauss, Boyas, \& Bivens, 2011). As Latino youth are disproportionately affected by teen pregnancy and sexually transmitted infections (STIs), prevention strategies that are culturally appropriate and effective in helping parents to provide their children with the knowledge to avoid risks and stay healthy could have a large impact. Thus, we implemented a community-based parent-child communication program in a predominately Latino community to measure community receptiveness to the reproductive health communication programming and to assess changes in parent comfort and skill around reproductive health discussions with their youth through self-reported parent-child connectedness.

\section{Methods}

\subsection{Participant Selection}

To be eligible for the parent-child communication programming, each participant was required to be a parent or guardian of a youth between the ages of 11 and 15 and reside in the 80219, 80204, or 80223 zip codes. Residents of these selected zip codes have higher rates of teen pregnancy, lower average socioeconomic status, and are predominantly Latino.

\subsection{Participant Characteristics}

Among the 65 parents enrolled in the program, most were female, 76.9\%; Hispanic, 95.4\%; married, 70.8\%; and had less than a high school education, $60.3 \%$ (Table 1). Sixty percent of parents attended all five classes of the program and $75.4 \%$ attended at least four of the five classes. Among parents attending the sessions, 96\% completed a pre-test survey, 93.8\% completed a first session post-test survey, and 92.3\% completed a survey after session five.

Follow-up surveys were administered at three and six months after programming. Fifty parents (76.9\%) completed at least one follow-up survey (66\% completed the three months survey, 63\% completed the six months 
Table 1. Baseline characteristics of parents.

\begin{tabular}{cc}
\hline Characteristic $(\boldsymbol{N}=\mathbf{6 5})^{*}$ & Percent \\
Gender $(\boldsymbol{n}=\mathbf{6 5})$ & 76.9 \\
Female & \\
Ethnicity $(\boldsymbol{n}=\mathbf{6 5})$ & 95.4 \\
Hispanic & 13.0 years \\
Mean target child's age $(\boldsymbol{n}=\mathbf{6 2})$ & \\
Target child's gender $(\boldsymbol{n}=\mathbf{6 1})$ & 37.7 \\
Female & \\
Education ( $\boldsymbol{n}=\mathbf{6 3})$ & 60.3 \\
Less than high school & 23.8 \\
High school graduate/GED & 6.3 \\
Some college, technical or trade school & 4.8 \\
Associates degree & 4.8 \\
Degree from 4 years college & \\
Marital status ( $\boldsymbol{n}=\mathbf{6 5})$ & 20.0 \\
Single & 70.8 \\
Married & 4.6 \\
Divorced & 4.6 \\
Other &
\end{tabular}

Note: "Some pretest data were missing for three parents.

survey, and 52.3\% completed both). No significant differences were identified among parents who completed only one of the follow-up surveys compared to those who completed both surveys (data not shown).

\subsection{Intervention Description}

Through a needs assessment of southwest Denver in 2010, the project team surveyed parents in a predominantly Latino and working class neighborhood. Concerns identified by parents related mainly to risky behaviors and how to address these issues with their youth. To address identified needs around parent-child communication, two complementary parent-child communication curricula were selected based on the following criteria: considered a promising or evidence-based practice, addressed reproductive health and teen pregnancy, and were culturally appropriate. The selected curricula were adapted to allow us to combine them together to create a cohesive five-week program.

We pilot tested the combined five-week program in the spring of 2011. Based on initial findings, we modified the curricula to increase participant interaction, refine the delivered messages, and reduce the use of written materials. To enhance the program's cultural relevance, all materials were translated into Spanish. To encourage attendance, classes were held in the neighborhood schools and included a complimentary meal, child care services, transportation as needed, and a $\$ 20$ grocery store gift card per class for adult parents and a $\$ 10$ gift card for youth when asked to attend. To accommodate participant work schedules, classes were held for two hours during weeknights for five weeks. Facilitators conducted reminder calls prior to each class. They also used these calls to address any questions or issues identified by the participants and, if needed, connected them with additional resources in the community. All parents received a certificate of program completion after the course was concluded.

\subsection{Program Curricula}

The parent-child communication program consisted of five two-hour sessions. For session 1, we used a program 
designed to increase parents' confidence in talking about reproductive health in order to give youth a solid foundation to make healthy decisions regarding their health and relationships ("Colorado Youth Matter", 2014). Topics discussed included sexuality, HIV/AIDS, STIs, and teen pregnancy. The Education, Training, \& Research (ETR) Associates' Parent-Child Connectedness program was used for sessions 2 through 5 ("ParentChild Connectedness (PCC): Bridging Research and Intervention Design”, 2012). This curriculum was adapted from a participant-led format to an instructor-led program for our community audience. Topics included parenting style (session 2), adolescent development (session 3), positive reinforcement (session 4), and active listening to provide emotional support (session 5). Facilitators invited youth to join their parents for the positive reinforcement session (session 4).

\subsection{Process Evaluation}

We conducted pilot testing to ensure that programming was suited to the interests and concerns of local parents. The pilot results suggested that programming was of an appropriate duration (five sessions), manageable in length (two hours), and met the literacy skills of the target participant group. For the pilot, recruitment, and implementation phase of the project, the project team formed a partnership with a local organization that was well-known and respected in the targeted community. Using multiple outreach approaches, this organization determined that the most successful recruitment strategy was networking through parent liaisons, friends, and family members.

As part of the implementation phase of the project, we monitored program fidelity via a tracking tool to assess how the facilitators' delivery of training topics followed the prescribed curriculum for each session. Findings indicated that facilitators taught the curriculum as prescribed $80.6 \%$ of the time, with adaptations occurring in earlier sessions based on parents' needs. Additionally, parents displayed interest in the topics and participated in the curricular activities.

\subsection{Survey Design and Data Collection}

To monitor changes in knowledge and behavior, we developed a series of data collection instruments that focused on communication across four time points (Hadley et al., 2009; Sales et al., 2008; Schuster et al., 2008). Survey questions were adapted from several previously published instruments. Four surveys were completed at the following points in time: baseline, one week after the completion of session 5 (at a graduation party where program completion certificates were distributed), and at three and six months after program completion. All surveys were administered in English or Spanish. The first two surveys were conducted in person by program staff. The three and six months surveys were conducted via a telephone interview.

At baseline, a 14-item survey was completed asking parents to rate their knowledge and ability to talk to their youth about reproductive health topics plus questions regarding perceived parent-child connectedness and the types of parent-child conversations that had occurred in the past month. Five additional demographic questions were also asked. A survey was administered one week after the completion of the fifth session and included the original 14 items as well as additional questions about the impact of the classes and if parents had used knowledge or skills from the classes with their children.

The three and six months follow-up consisted of an eight item survey that repeated questions from the baseline and post-fifth session surveys about parent-child conversations and the types of topics discussed. The survey asked parents about who had initiated conversations, the number of conversations, and which topics had been covered related to relationships, puberty, reproductive health, birth control, and STIs. Parents were asked their perceptions regarding parent-child connectedness. Lastly, they were asked to describe the impact the classes had on themselves and their family. We administered follow-up surveys by telephone and attempted at least three calls before considering the parent lost to follow-up. Parents received a \$25 gift card for completing each follow-up survey.

Table 2 provides a summary of the constructs that were included in all surveys. Constructs addressed were parents' ability to talk with their child about reproductive health topics, their relevant knowledge, the frequency of conversations, who initiated reproductive health conversations, the number and type of reproductive health topics discussed, attitudes/beliefs about parent-child relationship, parents' self-rated ability to talk to their youth about reproductive health topics, and parents' perceived confidence that they possessed the knowledge needed to talk to their youth about reproductive health. 
Table 2. Summary of constructs included in the study surveys.

\begin{tabular}{|c|c|c|c|c|c|}
\hline \multirow[b]{2}{*}{ Construct } & \multirow[b]{2}{*}{ Format } & \multicolumn{4}{|c|}{ Points in time collected } \\
\hline & & $\begin{array}{l}\text { Baseline } \\
\text { survey }\end{array}$ & $\begin{array}{l}\text { Post session } \\
5 \text { survey }\end{array}$ & $\begin{array}{l}3 \text { months } \\
\text { follow-up } \\
\text { survey }\end{array}$ & $\begin{array}{l}6 \text { months } \\
\text { follow-up } \\
\text { survey }\end{array}$ \\
\hline $\begin{array}{l}\text { Ability to talk to their child about } \\
\text { reproductive health topics }\end{array}$ & 7 point scale & $\mathrm{X}$ & $\mathrm{X}$ & $\mathrm{X}$ & $\mathrm{X}$ \\
\hline $\begin{array}{l}\text { Parent has knowledge they need to } \\
\text { discuss reproductive health }\end{array}$ & $\begin{array}{l}4 \text { point scale (strongly agree } \\
\text { to strongly disagree) }\end{array}$ & $\mathrm{X}$ & $\mathrm{X}$ & $\mathrm{X}$ & $\mathrm{X}$ \\
\hline Frequency of conversations & $\begin{array}{l}\text { Frequency rating for past } \\
\text { month ( } 4 \text { point scale from } \\
\text { never to daily) }\end{array}$ & $\mathrm{X}$ & $\mathrm{X}$ & $\mathrm{X}$ & $\mathrm{X}$ \\
\hline $\begin{array}{l}\text { - Child-initiated conversation about } \\
\text { reproductive health issue }\end{array}$ & & $\mathrm{X}$ & $\mathrm{X}$ & $\mathrm{X}$ & $\mathrm{X}$ \\
\hline $\begin{array}{l}\text { Child-initiated conversation about } \\
\text { non-reproductive health issue }\end{array}$ & $\begin{array}{l}\% \text { who initiated } \\
\text { conversation }\end{array}$ & $\mathrm{X}$ & $\mathrm{X}$ & $\mathrm{X}$ & $\mathrm{X}$ \\
\hline $\begin{array}{l}\text { - Parent-initiated conversation about } \\
\text { reproductive health issue }\end{array}$ & & $\mathrm{X}$ & $\mathrm{X}$ & $\mathrm{X}$ & $\mathrm{X}$ \\
\hline $\begin{array}{l}\text { Number of relationship and } \\
\text { reproductive health topics ever } \\
\text { discussed }\end{array}$ & $\begin{array}{ll}21 & \text { topics } \\
\text { - } & \text { relationships (3) } \\
\text { - } & \text { puberty (5) } \\
\text { - } & \text { sex (6) } \\
\text { - } & \text { birth control (4) } \\
\text { - } & \text { STIs (3) }\end{array}$ & $\mathrm{X}$ & $\mathrm{X}$ & $\mathrm{X}$ & $\mathrm{X}$ \\
\hline $\begin{array}{l}\text { Attitudes/beliefs about adolescents and } \\
\text { parent/child relationship }\end{array}$ & 5 questions (4 point scale) & $\mathrm{X}$ & $\mathrm{X}$ & $\mathrm{X}$ & $\mathrm{X}$ \\
\hline
\end{tabular}

\subsection{Analysis}

We generated descriptive statistics on baseline demographics of study parents. Using a repeated measures ANOVA, we assessed change in six constructs: parents' self-reported ability to talk with their youth about reproductive health topics, parent knowledge needed to discuss reproductive health, frequency of reproductive health conversations, attitudes and beliefs about adolescents and the parent/child relationship, number and type of topics ever discussed, and parents' self-reported connectedness with their youth. To assess the main effect of time, we assessed measured change in parent responses from baseline, after the completion of session 5 , and then either at the three months or six months follow-up periods. To adjust for incompleteness in follow-up data for some parents, we compared parent responses at baseline to responses after completion of session 5 and then either at the three months or six months follow-up periods. We used SAS version 9.1.3 software (SAS Institute, Inc., Cary, North Carolina) to conduct all analyses.

To determine parents' perceptions of the classes from a qualitative perspective, we compiled and coded the results of the open-ended question asked at the end of each of the follow-up surveys. Data were reviewed for themes and then aggregated to determine those most common to parent respondents.

\section{Results}

Parents queried from baseline through the follow-up contacts at three and six months reported significant improvements over time in how they rated their ability to communicate with their youth with respect to reproductive health topics, $p<.001$, as well as in their confidence that they have the knowledge needed to talk about reproductive health, $p<.01$ (Table 3). These results show that the training they have received continued to enable parents to have improved conversations with youth regarding reproductive health topics.

In addition to improvements in parents' perception of their abilities, parents reported that their communication patterns with their youth were more frequent and more likely to cover reproductive health topics (Table 4). Parents were also asked about the extent to which youth initiated conversations. Over time, increases were found in conversations initiated by youth regarding reproductive health at three months, $p<.01$, but not at six months; however, the frequency with which youth sought generic advice increased only at six months, $p<.05$. 
Table 3. Mean ratings (and standard errors) from analysis of variance assessing changes in parents' self-rated abilities at different follow-up intervals.

\begin{tabular}{|c|c|c|c|c|c|}
\hline & Variable & Baseline pretest & $\begin{array}{l}\text { After completion of } \\
\text { the } 5^{\text {th }} \text { session }\end{array}$ & $\begin{array}{l}3 \text { months } \\
\text { follow-up }\end{array}$ & $\begin{array}{l}6 \text { months } \\
\text { follow-up }\end{array}$ \\
\hline \multicolumn{6}{|c|}{$\begin{array}{l}\text { Rating of ability to talk to youth about } \\
\text { reproductive health topics }\end{array}$} \\
\hline$n=41$ & $F(3,120)=17.516$ & $4.00(.28)$ & $5.27(.19)$ & $5.73(.20)^{* * * *}$ & \\
\hline$n=37$ & $F(3,108)=12.73$ & $4.08(.29)$ & $5.24(.24)$ & & $5.73(.21)^{* * * *}$ \\
\hline \multicolumn{6}{|c|}{$\begin{array}{l}\text { Parents’ confidence that they possess the } \\
\text { knowledge needed to talk about } \\
\text { reproductive health }^{\ddagger}\end{array}$} \\
\hline$n=42$ & $F(3,123)=7.60$ & $2.07(.15)$ & $2.21(.09)$ & $2.33(.09)^{* * *}$ & \\
\hline$n=37$ & $F(3,108)=4.74$ & $2.22(.12)$ & $2.27(.10)$ & & $2.30(.09)^{* * *}$ \\
\hline
\end{tabular}

Note: ${ }^{*} p<.05 ;{ }^{* *} p<.01 ;{ }^{* * *} p<.001 . n=$ number of parents contacted at each of the respective follow-up periods (e.g., 3 months and 6 months); †“Ability to talk to youth about reproductive health topics” was a seven point Likert scale with "7” being "excellent” and “ 1 ” being terrible; ${ }^{\ddagger}$ "Parents” confidence that they possessed the knowledge needed to talk about reproductive health" was a four point Likert scale with "3” being "strongly agree" and " 0 " being "strongly disagree"; ${ }^{\S}$ Fifty parents (76.9\%) completed at least one follow-up survey (66\% completed the three month survey, 63\% completed the six months survey, and 52\% completed both). No significant differences were identified among parents who completed only one of the follow-up surveys compared to those who completed both surveys.

In addition, parents were asked about the frequency with which they initiated conversations and the topics covered during these talks. Within the three and six months follow-up groups, parents reported more frequent conversations with their youth around reproductive health topics from never to one to two talks, 3 months group, $p<.05 ; 6$ months group, $p<.01$. In the number of topics covered, parents showed an increase over time in the aggregate number of reproductive health topics parents discussed, 3 months group, $p<.001 ; 6$ months group, $p$ $<$.001. Most importantly, parents reported increases in the number of specific topics covered during their conversations with youth to include: relationships, 6 months group, $p<.01$; puberty, 3 months group, $p<.01$, 6 months group $p<.001$; reproductive health, 3 month group, $p<.001,6$ months group, $p<.001$; birth control, 3 month group, $p<.001$, 6 months group, $p<.001$; and STIs, 3 months group, $p<.001$, 6 months group, $p<.001$. Table 2 provides a detailed listing of the number of topics parents were queried about within each of these categories. Finally, parents reported significant improvements in their degree of connectedness with their youth, 3 months group, $p<.05 ; 6$ months group, $p<.05$. Among all topics, we observed the greatest increase in number of topics covered for reproductive health topics such as reproductive health, birth control, and STIs (Table 4).

Qualitatively, parents were asked about the impact of the classes for themselves and their families. Themes identified included self-reported communication improvements, better relationships with their youth, increased self-confidence, and more knowledge about adolescent development and reproductive health topics. Specifically, parents reported learning how to talk, listen, and pay attention to their youth and to read their youth's body language. They reported learning how to ask questions that invited sharing and how to respond to their youth's answers. Parents reported that, by using the knowledge about adolescent development, behavior, and the various reproductive health topics covered, they were able to increase their self-confidence when talking to their youth about reproductive health. Parents reported feeling less reserved and embarrassed talking about reproductive health and feeling more confident in sharing information with their youth. Overall, many parents reported that the curricula provided them with important skills needed to improve their relationship with their youth.

\section{Discussion}

Research has shown that parent-child communication is an important factor in influencing youth decision-making around reproductive health, but few programs targeting this factor have been evaluated (Akers, Holland, \& Bost, 2011; Kirby \& Miller, 2002), signifying a need for additional study in this area. Youth-focused educational programming is commonly offered, but a lack of parent-child communication programming for parents (Hamilton, 2012) creates a gap in addressing community needs, with particularly large ramifications for the Latino community where teen pregnancy rates are high (Kumpfer, 2010). In this study, we were able to create a five-week curriculum that improved parents’ ability to communicate and connect with their youth by merging complementary curricula that focus on building skills, knowledge, and confidence related to parent-child com- 
munication and emphasizing reproductive health. As Latinas have higher rates of teen birth (Kost, 2012) and there is a lack of parent-child communication programming targeted toward Latino populations (Cardoza et al., 2012; Murphy-Erby et al., 2011), this study conducted in a predominately Latino community with high rates of teen births offers a promising approach to address these gaps among Latino parents.

Table 4. Mean ratings (and standard errors) from analysis of variance assessing changes in parent-child communication at baseline and at different follow-up intervals.

Baseline pretest $\quad 3$ months $\quad 6$ months

\section{Frequency of youth asking parents for generic advice}

$$
\begin{array}{ll}
n=43 & \mathrm{~F}(2,84)=.77 \\
n=38 & \mathrm{~F}(2,74)=3.50
\end{array}
$$

$1.44(.18)$

Frequency of youth initiating conversations about reproductive health topics ${ }^{\dagger}$

$$
n=43 \quad \mathrm{~F}(2,84)=6.90
$$

$n=39 \quad \mathrm{~F}(2,76)=1.71$

$1.14(.12)^{*}$

$$
\begin{array}{ll}
n=43 & \mathrm{~F}(2,84)=3.45 \\
n=39 & \mathrm{~F}(2,76)=5.02
\end{array}
$$$$
1.14(.12)^{* *}
$$

Frequency of parents initiating conversations about reproductive health ${ }^{\dagger}$

discussed

$$
\begin{aligned}
& n=43 \quad \mathrm{~F}(2,84)=21.01 \\
& n=39 \quad \mathrm{~F}(2,76)=23.10
\end{aligned}
$$

\section{Percent of relationship topics discussed}

$$
n=43 \quad \mathrm{~F}(2,84)=2.20
$$$$
n=39 \quad \mathrm{~F}(2,76)=6.87
$$$$
71.32(4.40)
$$

Percent of puberty topics discussed

$$
n=43 \quad \mathrm{~F}(2,84)=7.40
$$$$
n=39 \quad \mathrm{~F}(2,76)=9.56
$$

$n=38 \quad \mathrm{~F}(2,74)=13.80$

\section{Percent of STI topics discussed}

$n=43 \quad \mathrm{~F}(2,84)=15.58$

$n=38$

$$
\mathrm{F}(2,74)=11.70
$$

$72.87(5.50)^{* * *}$

$64.04(6.50)^{* * *}$

\section{Parents' perceived connectedness with their child ${ }^{\ddagger}$}

$$
n=42 \quad \mathrm{~F}(2,82)=3.88
$$

$14.44(.72)^{* * * *}$
$14.28(.88)^{* * *}$

$$
14.28(.88)^{* * *}
$$$$
75.21(4.54)^{* *}
$$

$63.72(3.72)^{* *}$

$70.26(4.08)^{* * *}$

$71.80(4.98)^{* * *}$

$63.95(5.30)^{* * *}$

$57.24(6.32)^{* * * *}$

$n=37 \quad \mathrm{~F}(2,72)=3.35$

Note: ${ }^{*} p<.05 ;{ }^{* *} p<.01 ;{ }^{* * *} p<.001 . n=$ number of parents contacted at each of the respective follow-up periods (e.g., 3 months and 6 months); ${ }^{\dagger}$ Frequency of conversations was measured on a three point Likert scale with " 3 ” being daily, "2" being weekly and " 1 ” being 1 - 2 times in the past month. Parents were given a "yes-no" option to indicate which topics were ever discussed within a menu of 21 topics; ${ }^{\ddagger}$ Connectedness was measured on a 10 point Likert scale with "10" being "total connectedness"; ${ }^{\S}$ Fifty parents (76.9\%) completed at least one follow-up survey (66\% completed the three months survey, $63 \%$ completed the six months survey, and 52\% completed both). No significant differences were identified among parents who completed only one of the follow-up surveys compared to those who completed both surveys. 
The programming offered parents specific tools to be able to successfully communicate with their youth about teen pregnancy and youth reproductive health. Understanding cultural norms around acceptability of provision of programming to address parental communication was critical to the implementation of this type of training. Prior to program implementation, a trusted community-based organization conducted a community needs assessment to determine what was needed by the community to address this issue. By using this preparatory work to select and modify two pre-existing program curricula, our five-week, parent-child communication program was well-received by study parents, with high class attendance rates throughout the program. Additionally, at the completion of the programming, some parents requested further support and resources, illustrating the importance of and need for this type of programming in the community.

To ensure that parents participated, it was important to respond to potential barriers to program participation by creating an engaging and supportive environment for parents. Complimentary meals coupled with the interactive format of the curricula offered numerous sharing opportunities for parents to develop trusting relationships with each other and staff, which contributed to participant retention. Reminder calls made by program facilitators also enhanced attendance and further built trust between the facilitators and parents. These tactics have been shown to increase participant retention and engagement in parent-child communication programming around reproductive health (Armistead et al., 2004) and we believe that designing the provision of the program to support parents in feeling valued and engaged was central to the improved outcomes and sustained results of this study.

There were strengths and limitations associated with this study. The measures used to assess retention of parent-child communication skills demonstrated significant increases in the number of conversations initiated, the types of topics addressed, and parents' self-assessment of connectedness to their youth. However, whereas the program proved to be popular and well-attended, it is unclear to what extent self-selection by parents impacted the program outcomes. The monetary incentives offered by the program were designed to make the programming accessible to all parents, but may have motivated certain parents to attend the program, which may have also affected the outcomes found. Additionally, the significant increases in the number of conversations initiated and the topics covered were generated through parent self-report and do not include information from youth regarding resulting changes in their attitudes or behavior. Participants completed a consent procedure prior to the program's start; however, as the purpose of the study was program evaluation, Institutional Review Board approval was not considered necessary. Nonetheless, the rates at which conversations occurred and the number of topics covered increased for groups at both follow-up timeframes, suggesting that the training had lasting benefit for parents.

\section{Conclusion}

Our findings suggest that parent-child communication improved as a result of using a five-week parent training program and that this program was successful in generating improvement in skills, knowledge, and the confidence needed by parents to talk with their youth about reproductive health. Future comparative studies are needed to more rigorously assess our findings, particularly in high-risk populations such as the one targeted by this study. Using models developed to offer comprehensive reproductive health education programming for youth (Edouard \& Edouard, 2012), large-scale parent-child communication programming that complements existing youth programming needs be implemented and evaluated to develop a more holistic approach for reducing teen pregnancy.

\section{References}

Akers, A. Y., Holland, C. L., \& Bost, J. (2011). Interventions to Improve Parental Communication about Sex: A Systematic Review. Pediatrics, 127, 494-510. http://dx.doi.org/10.1542/peds.2010-2194

Albert, B. (2012). With One Voice 2012: America's Adults and Teens Sound off about Teen Pregnancy. Washington, DC: The National Campaign to Prevent Teen and Unplanned Pregnancy.

Armistead, L., Clark, H., Barber, C. N., Dorsey, S., Hughley, J., Favors, M., \& Wyckoff, S. (2004). Participant Retention in the Parents Matter! Program: Strategies and Outcome. Journal of Child and Family Studies, 13, 67-80. http://dx.doi.org/10.1023/B:JCFS.0000010491.03013.5e

Cardoza, V. J., Documét, P. I., Fryer, C. S., Gold, M. A., \& Butler III, J. (2012). Sexual Health Behavior Interventions for U.S. Latino Adolescents: A Systematic Review of the Literature. Journal of Pediatric and Adolescent Gynecology, 25, 
136-149. http://dx.doi.org/10.1016/j.jpag.2011.09.011

Catalano, R. F., Gavin, L. E., \& Markham, C. M. (2010). Future Directions for Positive Youth Development as a Strategy to Promote Adolescent Sexual and Reproductive Health. Journal of Adolescent Health, 46, S92-S96. http://dx.doi.org/10.1016/j.jadohealth.2009.12.026

Colorado Youth Matter (2014). http://www.coloradoyouthmatter.org

DiClemente, R. J., Wingood, G. M., Crosby, R., Cobb, B. K., Harrington, K., \& Davies, S. L. (2001). Parent-Adolescent Communication and Sexual Risk Behaviors among African American Adolescent Females. The Journal of Pediatrics, 139, 407-412. http://dx.doi.org/10.1067/mpd.2001.117075

Edouard, E., \& Edouard, L. (2012). Application of Information and Communication Technology for Scaling up Youth Sexual and Reproductive Health [Report]. African Journal of Reproductive Health, 16, 197.

Hadley, W., Brown, L. K., Lescano, C. M., Kell, H., Spalding, K., Diclemente, R., \& Project, S. S. G. (2009). Parent-Adolescent Sexual Communication: Associations of Condom Use with Condom Discussions. AIDS and Behavior, 13, $997-1004$. http://dx.doi.org/10.1007/s10461-008-9468-z

Hamilton, B. (2012). Births: Preliminary Data for 2011. National Vital Statistics Reports, 61, Table 2.

Kirby, D., \& Miller, B. C. (2002). Interventions Designed to Promote Parent-Teen Communication about Sexuality. New Directions for Child \& Adolescent Development, 2002, 93-110. http://dx.doi.org/10.1002/cd.52

Kost, K. (2012). U.S. Teenage Pregnancies, Births and Abortions, 2008: National Trends by Age, Race and Ethnicity. S. Henshaw (Ed.), New York: Guttmacher Institute.

Kumpfer, K. L., Whiteside, H. O., Greene, J. A., \& Allen, K. C. (2010). Effectiveness Outcomes of Four Age Versions of the Strengthening Families Program in Statewide Field Sites. Group Dynamics: Theory, Research, and Practice, 14, $211-229$. http://dx.doi.org/10.1037/a0020602

Levine, S. B. (2011). Facilitating Parent-Child Communication about Sexuality. Pediatrics in Review, 32, 129-130. http://dx.doi.org/10.1542/pir.32-3-129

Markham, C. M., Tortolero, S. R., Peskin, M. F., Shegog, R., Thiel, M., Baumler, E. R., Addy, R. C., Escobar-Chaves, S. L., Reininger, B., \& Robin, L. (2012). Sexual Risk Avoidance and Sexual Risk Reduction Interventions for Middle School Youth: A Randomized Controlled Trial. Journal of Adolescent Health, 50, 279-288. http://dx.doi.org/10.1016/j.jadohealth.2011.07.010

Miller, K. S., Lin, C. Y., Poulsen, M. N., Fasula, A., Wyckoff, S. C., Forehand, R., Long, N., \& Armistead, L. (2011). Enhancing HIV Communication between Parents and Children: Efficacy of the Parents Matter! Program. AIDS Education \& Prevention, 23, 550-563. http://dx.doi.org/10.1521/aeap.2011.23.6.550

Murphy-Erby, Y., Stauss, K., Boyas, J., \& Bivens, V. (2011). Voices of Latino Parents and Teens: Tailored Strategies for Parent-Child Communication Related to Sex. Journal of Children and Poverty, 17, 125-138. http://dx.doi.org/10.1080/10796126.2011.531250

Parent-Child Connectedness (PCC): Bridging Research and Intervention Design (2012). http://recapp.etr.org/recapp/index.cfm?fuseaction=pages.TopicsInBriefDetail\&PageID=57

Resnick, M. D., Bearman, P. S., Wm. Blum, R., Bauman, K. E., Harris, K. M., Jones, J. et al. (1997). Protecting Adolescents from Harm: Findings from the National Longitudinal Study on Adolescent Health. Journal of the American Medical Association, 278, 823-832. http://dx.doi.org/10.1001/jama.1997.03550100049038

Sales, J. M., Milhausen, R. R., Wingood, G. M., Diclemente, R. J., Salazar, L. F., \& Crosby, R. A. (2008). Validation of a Parent-Adolescent Communication Scale for Use in STD/HIV Prevention Interventions. Health Education \& Behavior, 35, 332-345. http://dx.doi.org/10.1177/1090198106293524

Schuster, M. A., Corona, R., Elliott, M. N., Kanouse, D. E., Eastman, K. L., Zhou, A. J., \& Klein, D. J. (2008). Evaluation of Talking Parents, Healthy Teens, a New Worksite Based Parenting Programme to Promote Parent-Adolescent Communication about Sexual Health: Randomised Controlled Trial. British Medical Journal, 337, a308. http://dx.doi.org/10.1136/bmj.39609.657581.25

Teen Childbearing Cost Taxpayers \$10.9 Billion in 2008: New National and State-by-State Data Released (2011). The National Campaign to Prevent Teen and Unplanned Pregnancy.

Wildsmith, E., Manlove, J., Jekielek, S., Moore, K. A., \& Mincieli, L. (2012). Teenage Childbearing among Youth Born to Teenage Mothers. Youth \& Society, 44, 258-283. http://dx.doi.org/10.1177/0044118X11398366 
Scientific Research Publishing (SCIRP) is one of the largest Open Access journal publishers. It is currently publishing more than 200 open access, online, peer-reviewed journals covering a wide range of academic disciplines. SCIRP serves the worldwide academic communities and contributes to the progress and application of science with its publication.

Other selected journals from SCIRP are listed as below. Submit your manuscript to us via either submit@scirp.org or Online Submission Portal.
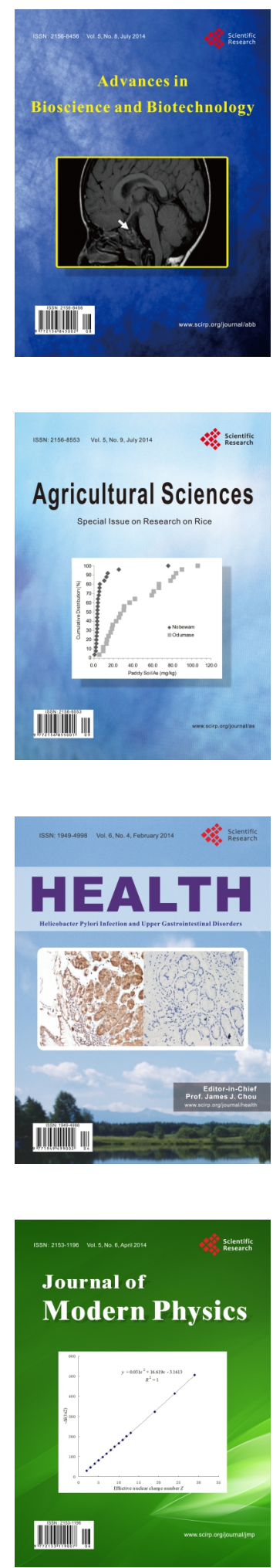
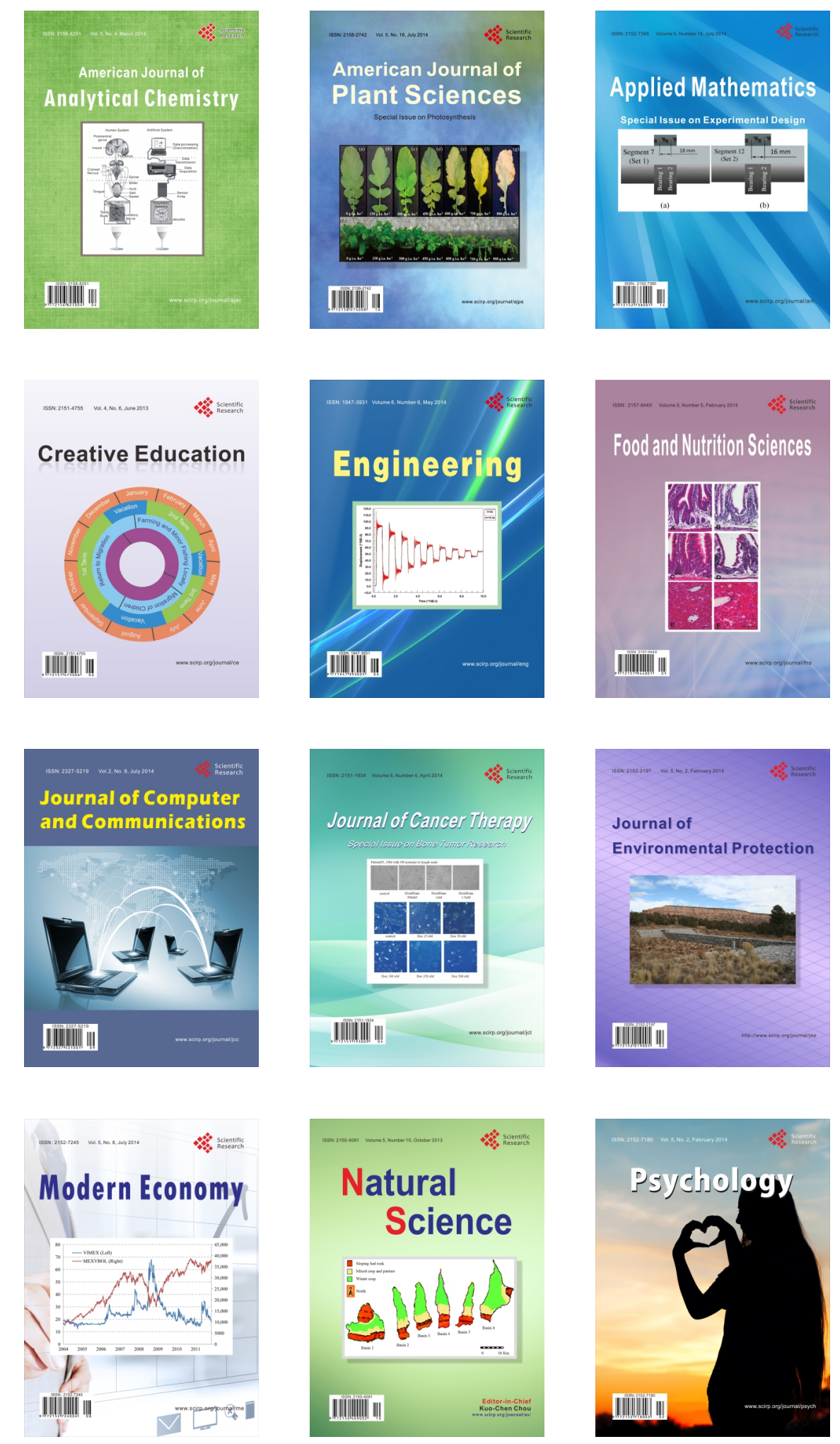